\title{
Commentary on the paper by Mennitti et al., Lipids in Health Disease 2014, 13:26
}

\author{
Ben AR Lina
}

\begin{abstract}
In a recent study by Mennitti et al., the authors concluded that oligofructose supplementation during pregnancy and lactation impairs offspring development.

However, the data reported in this article have limitations and should be interpreted with caution. A conclusion with respect to offspring development does not seem justified.
\end{abstract}

Keywords: Oligofructose, Offspring development

\section{Background}

This commentary challenges the conclusion by Menitti et al. [1] in a recent article entitled: 'Oligofructose supplementation during pregnancy and lactation impairs offspring development and alters the intestinal properties of 21-d-old pups'.

In this study, groups of 4 pregnant female Wistar rats were given $10 \%$ oligofructose in the diet during pregnancy and lactation. Oligofructose was incorporated at the expense of corn starch in AIN-93 based diet. On the day of delivery, litters were culled to 8 pups each.

During the 21 day lactation period, reduced body weight, body weight gain and reduced naso-anal length were reported in the offspring of dams fed the $10 \%$ oligofructose diet. In addition, retroperitoneal adipose tissue and serum concentrations of free fatty acids were reported to be decreased in pups of this group. The authors concluded that oligofructose supplementation during pregnancy and lactation impairs offspring development.

\section{Main text}

In this commentary I would like to challenge the correctness of the conclusion in the paper by Mennitti et al., 2014 that oligofructose supplementation during pregnancy and lactation impairs offspring development. In my opinion, this paper suffers from several serious limitations.

Correspondence: ben.lina@tno.triskelion.nl

TNO Triskelion, Utrechtseweg 48, P.O. Box 844, 3700 AV Zeist, Utrecht,

The Netherlands

\section{Group size}

There were only 4 dams per group, whereas, for a meaningful evaluation, international guidelines require much larger group sizes e.g. a minimum of 8 pregnant females for a Reproduction/Developmental Toxicity Screening Test (OECD 421) [2], at least 16 pregnant females per group for a Prenatal Developmental Toxicity Study (OECD 414) [3], or 20 pregnant rats for Developmental Toxicity Studies according to EPA [4] or FDA [5].

\section{Maternal data}

Apart from the statement that ' $10 \%$ oligofructose supplementation triggered diarrhea in dams', no information on maternal weight, feed intake or maternal toxicity was provided. This lack of information hampers evaluation of effects in pups.

\section{Experimental diets}

The experimental diets were stated to be isocaloric $(4.0 \mathrm{kcal} / \mathrm{g})$. However, assuming an energetic value of $1.5 \mathrm{kcal} / \mathrm{g}$ for oligofructose and $4 \mathrm{kcal} / \mathrm{g}$ for corn starch, the incorporation of $10 \%$ oligofructose at the expense of corn starch results in a lower energetic value of the test diet (3.75 versus $4.0 \mathrm{kcal} / \mathrm{g}$ diet in controls). Because, moreover, no feed intake figures were presented, it is not possible to compare the energy intake in the different groups.

\section{Number of litters, litter size and selection of the pups}

No information was provided on the selection of the pups on the day of delivery, nor on the number of selected pups 
per litter or on litter size. Litter size is an important determinant for the growth rate of pups. Because of this lack of information, no conclusion can be drawn with respect to the growth and size of the pups.

\section{Number of pups per group}

Only a very limited number of pups was evaluated. According to the information provided, maximally 32 pups could be available per group. However, only 21 per group were evaluated for growth and length, while determination for adipose tissue, liver weight and serum free acid levels were conducted in 10-15 pups. The reason for selecting or rejecting pups was not reported.

\section{Conclusion}

The data reported in this article have limitations and should be interpreted with caution. A conclusion with respect to offspring development does not seem justified.

\section{Competing interests}

Author of this commentary is employed by TNO Triskelion. TNO Triskelion, a subsidiary of the Netherlands Organization for Applied Scientific Research, serves as independent trusted third party CRO. BENEO GmbH, Obrigheim/ Pfalz, Germany commissioned TNO Triskelion to review the article by Mennitti et al. [1] and to submit the commentary for publication.

Received: 12 May 2014 Accepted: 18 June 2014

Published: 24 June 2014

\section{References}

1. Mennitti LV, Oyama LM, Lopez de Oliveira J, Hachul ACL, Santamarina AB, de Santana AA, Okuda MH, Ribeiro EB, da Penha Oller do Nascimento Nascimento CM, Pisani LP: Oligofructose supplementation during pregnancy and lactation impairs offspring development and alters the intestinal properties of 21-d-old pups. Lipids Health Dis 2014, 13:26.

2. OECD Guideline for the Testing of Chemicals 421: Reproduction/ Developmental Toxicity Screening Test, adopted $27^{\text {th }}$ July 1995. 1995

3. OECD Guideline for the Testing of Chemicals 414: Prenatal Developmental Toxicity Study, adopted 22 $2^{\text {nd }}$ January 2001. 2001.

4. EPA Health Effects Test Guidelines OPPTS 870.3700: Prenatal Developmental Toxicity Study. OPPTS Harmonized Test Guidel 1998, 1(Series 870).

5. FDA Toxicological Principles for the Safety Assessment of Food Ingredients: Chapter IV.C.9.b. Guidelines for Developmental Toxicity Studies, Redbook. 2000

doi:10.1186/1476-511X-13-103

Cite this article as: Lina: Commentary on the paper by Mennitti et al., Lipids in Health Disease 2014, 13:26. Lipids in Health and Disease 2014 13:103.

\section{Submit your next manuscript to BioMed Central and take full advantage of:}

- Convenient online submission

- Thorough peer review

- No space constraints or color figure charges

- Immediate publication on acceptance

- Inclusion in PubMed, CAS, Scopus and Google Scholar

- Research which is freely available for redistribution 